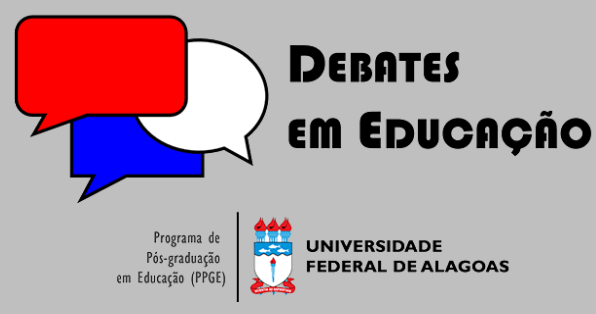

ISSN Eletrônico 2175-6600

Vol. 13 I N. 31 I Jan./Abr. I 2021

Clarice Zientarski

9 iD

Universidade Federal do Ceará (UFC) claricezientarski@yahoo.com.br

\section{OS RUMOS DA EDUCAÇÃO E DO ENSINO SUPERIOR PÚBLICO BRASILEIRO NOS ANOS 1990 E PÓS - 2016}

\section{RESUMO}

O trabalho trata sobre as similitudes que se apresentam entre programas e projetos do Governo Federal pós-2016 para a educação e o ensino superior público brasileiro, e as ações emanadas a partir da contrarreforma de Estado dos anos de 1990.Trata-se de um estudo bibliográfico e documental que busca amparo na dialética materialista histórica. Conclui que as políticas para a educação e ensino superior, até o momento, apresentam similitudes com as estabelecidas pelos governos na década de 1990, porém têm sido mais discrepante em alguns aspectos, especialmente ao tentar desqualificar o trabalho desenvolvido nas IFES, comprometendo as pesquisas, o ensino e a extensão.

Palavras-chave: Ensino Superior Público. Educação Superior. Década de 1990. Pós 2016

\section{THE PATHS OF BRAZILIAN PUBLIC EDUCATION AND HIGHER EDUCATION IN THE 1990 AND POST - 2016}

\begin{abstract}
The work deals with the similarities that exist between programs and projects of the Federal Government post-2016 for education and public higher education in Brazil, and the actions emanating from the counterreform of the state of the 1990s. This is a study bibliographic and documentary study that seeks support in the historical materialist dialectic. It concludes that the policies for education and higher education, so far, have similarities with those established by governments in the 1990s, but they have been more discrepant in some aspects, especially when trying to disqualify the work developed at IFES, compromising research, teaching and extension.
\end{abstract}

Keywords Public Higher Education. College education. 1990s. Post 2016

Submetido em: $14 / 07 / 2020$

Aceito em: 18/09/2020

Publicado em: 26/06/2021

d. https://doi.org/10.28998/2175-6600.2021v13n31p551-576 


\section{INTRODUÇÃO}

Esse trabalho tem por objetivo identificar as similitudes que se apresentam entre alguns programas e projetos do Governo Federal pós-2016 para a educação e o ensino superior público brasileiro, e as ações emanadas a partir da contrarreforma de Estado dos anos de 1990 (BEHRING,2008). Trata-se de um estudo bibliográfico e documental fundamentado na dialética materialista histórica definida por Frigotto (1999), como uma postura, uma concepção de mundo, como um método (que permite a apreensão radical da realidade) e como uma práxis, à medida que possibilita a busca da transformação, de novas sínteses no âmbito do conhecimento e da realidade histórica. Neste sentido, busca contribuir para a reflexão sobre a temática ao enfatizar as propostas efetivadas após 2016, que corroboram com o desmantelamento da educação (FREITAS, 2018), e do ensino público (SAVIANI, 2008), e as ações impetradas na década de 1990 no Brasil, com a "Reforma do Estado" (BRESSER PEREIRA, 1997, p. 7).

Esses programas envolveram transformações nas relações de trabalho, bem como veicularam a desconstrução dos serviços públicos, a desqualificação de funcionários, reverberando no ensino público por meio dos atos do governo que atingiram em cheio as universidades públicas. No período pós 2016 observa-se, por um lado, a diminuição da oferta de vagas nas universidades públicas e institutos federais e, por outro lado, a oportunidade esperada por grupos privados internacionais, em alguns casos associados a grupos brasileiros, de ampliarem sua presença no ensino superior no país. (FIGUEIREDO, 2017).

A contrarreforma ${ }^{1}$ conforme defende Behring (2008) surge em um contexto de minimização do papel intervencionista do Estado no que diz respeito às políticas sociais e à redução ou ao desmantelamento das políticas de proteção e de direitos humanos. Trata-se, portanto, de um desmonte da estrutura estatal, com o objetivo de fazer retroceder os direitos sociais, conquistados pela classe trabalhadora por meio de lutas. Esta concepção se apresenta como uma possibilidade de desenvolvimento econômico, de modernização e racionalização, criando uma ideia de superação do desemprego, de contenção da hiperinflação e de bom uso do dinheiro público.

\footnotetext{
${ }^{1}$ Nesse trabalho utiliza-se como referência, por um lado, a expressão contrarreforma empregada por Elaine Behring, tendo em vista a concordância com a autora no que se relaciona a um período que "implicou um profundo retrocesso social, em benefício de poucos" e, ainda, a "auto-referencia dos apologistas, os quais insistem em apontar o projeto da era FHC como reforma, é uma espúria e ideológica ressemantificação", por outro lado, quando se trata das escritas de Bresser Pereira, -"apologista", a expressão utilizada é Reforma do Estado dos anos 1990.
} 
Nesse prisma, o Estado brasileiro presente no processo de globalização, harmonizado com as determinações do liberalismo econômico na intensificação da privatização da esfera pública, nas mudanças da legislação trabalhista e previdenciária, e na desregulamentação econômica, coloca essas ações como necessárias ao desenvolvimento do capital e ao "bem comum" - salvar aposentadoria, garantir escolas de qualidade etc. $\mathrm{O}$ que foi feito, no entanto, é justamente o contrário, pois com a demissão de funcionários públicos não estáveis, a adoção da medida de demissão voluntária (PDV), a privatização e a aprovação da reforma administrativa, o fechamento e a privatização de organismos estatais, conduziram a um enxugamento de pessoal nos setores públicos (POCHMANN, 2007).

No Brasil, conforme Bresser Pereira (1997), "a grande tarefa dos anos de 1990" foi a reforma ou a reconstrução do Estado, para que "este pudesse realizar não apenas suas tarefas clássicas de garantia da propriedade e dos contratos, mas também seu papel de garantidor dos direitos sociais e de promotor da competitividade". (BRESSER PEREIRA, 1997, p. 7 - 8). Como se observa, nessa reforma defende-se a delimitação das funções do Estado, "reduzindo seu tamanho em termos principalmente de pessoal através de programas de privatização, terceirização e 'publicização'” (Idem, 1997, p. 7 - 8).

No contexto atual (2016 em diante) assiste-se no Brasil à defesa e implantação de projetos e programas que apresentam similitudes com os impetrados na década de 1990, que atingem a classe trabalhadora e as universidades públicas, como, por exemplo: a decisão do Supremo Tribunal Federal - STF, de que os dias parados por greve de trabalhador devem ser descontados, exceto se houver acordo de compensação; a aprovação irrestrita da terceirização, que possibilita inclusive que as atividades fins sejam terceirizadas, sancionada na Lei no 13.429/17 e confirmada pelo STF em 2018; aplicação de formas de contratação alternativas por meio da Lei $n^{\circ} 13.417$ (como o trabalho intermitente, no qual o trabalhador é remunerado pelo período de trabalho e o pagamento de férias e décimo terceiro proporcional); aprovação da Lei Antiterrorismo pelo Congresso Nacional considerando como atos de terror: incendiar, depredar, destruir ou explodir meios de transporte, ou outro bem público ou privado. (BRASIL, SENADO, 2016). Além das decisões tomadas em nível de executivo e legislativo, que, transformadas em leis, prejudicam a classe trabalhadora, assiste-se a uma nova caça às bruxas, com intensa perseguição aos servidores públicos, por meio de demissões, transferências, assédio moral, humilhações, dentre outras formas de culpabilização destes, considerados 
parasitas do orçamento público (o ministro da economia Paulo Guedes, por exemplo, fez esta comparação no mês de fevereiro de 2020).

Em relação à educação, portanto, a Lei $n^{\circ}$. 13.415, de 16 de fevereiro de 2017altera a Lei $n^{\circ}$ 9.394, de 20 de dezembro de 1996, que estabelece as Diretrizes e Bases da Educação Nacional, a Lei no 11.494, de 20 de junho 2007, que regulamenta o Fundo de Manutenção e Desenvolvimento da Educação Básica e de Valorização dos Profissionais da Educação-FUNDEB, o Decreto-Lei no 236, de 28 de fevereiro de 1967 que revoga a Lei $n^{\circ} 11.161$, de 5 de agosto de 2005 e institui a Política de Fomento à Implementação de Escolas de Ensino Médio em Tempo Integral; a defesa de uma escola "sem Partido" que tramita há algum tempo; a Resolução CNE/CP n ${ }^{2}$, de 22 de dezembro de 2017, que institui e orienta a implantação da Base Nacional Comum Curricular a ser respeitada obrigatoriamente ao longo das etapas e respectivas modalidades no âmbito da Educação Básica; a Resolução nº 2 de 2019 que altera a Resolução CNE/CP n² 2/2015, e estabelece Diretrizes Curriculares e Base Nacional Comum para a formação inicial e continuada de professores da educação básica, à luz das demandas educacionais contemporâneas e das proposições contidas na BNCC; a proposta da homeschooling (Educação domiciliar), que contribui com a privatização da oferta da educação no que se constitui como a etapa obrigatória de escolarização; ainda, o Projeto FUTURE-SE do Governo Federal, lançado em 17 de julho de 2019, dentre outras leis e projetos que afetam especialmente a formação da classe trabalhadora.

Nessa perspectiva, este trabalho se divide em sessões: na primeira discute a contrarreforma do Estado dos anos de 1990; na segunda, discorre sobre a educação superior na década de 1990 no Brasil; na terceira, de forma breve, apresenta o Estado brasileiro pós impeachment de Dilma Roussef e os caminhos da educação superior sob a égide e batuta da privatização e do contingenciamento de recursos, em correlação com as agendas internacionais, com a descentralização, a publicização e privatização e, ainda, discute as similitudes entre as propostas para as universidades e ensino superior público da década de 1990 e as estabelecidas pós 2016. Por fim, expõe parcialmente, o resultado das discussões.

\section{A CONTRARREFORMA DO ESTADO DOS ANOS 1990}

A partir da década de 1990, o Brasil vivencia uma investida neoliberal que, ao avançar, provoca transformações nas relações de trabalho, bem como veicula a desconstrução dos serviços públicos e a desqualificação de funcionários. Essa ofensiva 
tornou-se muito forte durante o governo do Presidente Fernando Collor, sendo consolidada no Governo Fernando Henrique Cardoso (1995-2002) com a efetiva redução do tamanho do Estado brasileiro, por meio da implantação definitiva do neoliberalismo como novo modelo econômico. Nesse período, se estabeleceu um processo de descrédito dos serviços públicos, de difamação e culpabilização de servidores públicos com o objetivo de criar as condições objetivas para a implantação do projeto de reformas na administração e no serviço público (MASCARENHAS, 2000). Para realizar esse feito o governo contou com a influência da mídia, criando um aparato ideológico para obter o apoio da população.

Assim, são atribuídas aos servidores as "características de comodismo, improdutividade, incompetência e descomprometimento com as práticas do serviço público e atuação profissional". Estes são, 'atributos próprios à imagem do velho 'barnabé', agora acrescentado de outros traços, mais 'modernos', como 'marajá' 'aproveitadores"' etc. (MASCARENHAS, 2000, p.123). Conjuntamente com os argumentos pejorativos deste governo aos servidores, realizou-se uma contrarreforma de Estado, cujas ações contribuíram para a implantação do projeto neoliberal no Brasil (BEHRING, 2008). Ao avocar o princípio de desenvolvimento econômico, apresenta em sua defesa o princípio do "[...] livre acesso à mundialização do capital, [que] segundo os arautos neoliberais, poderia contribuir para a constituição de um novo padrão de financiamento e de investimento do capitalismo brasileiro" (GOLDESTEIN, 1994, p. 99).

O Estado brasileiro assume a postura de mercantilização e de incorporação do modelo econômico, na pulverização dos sindicatos, no arrefecimento da luta sindical, no atrelamento destes ao governo em contradição ao crescimento do número de sindicatos e de sindicalizados. As medidas do governo, ao serem incorporadas na administração do serviço público, levaram à extinção de órgãos, à disponibilização e demissão de funcionários públicos federais. Provocaram, portanto, a perda das conquistas trabalhistas, o rebaixamento dos salários e o crescimento do desemprego, resultando em miséria, escravidão e pauperismo. Por essa razão, ocorrem inúmeros conflitos que envolvem as relações entre trabalho e capital, os quais, em parte, são minimizados por meio de programas sociais afirmativos, indicando que o Estado neoliberal, no contexto do modo de produção capitalista, contribui para ocultar as relações e os conflitos presentes entre o capital e o trabalho.

A posse de Fernando Collor de Mello na Presidência da República, em 1990, traz para o Brasil, a lógica implementada por Thatcher, aproximadamente dez anos antes, 
inserindo o país "na economia mundial, com amargas consequências aos brasileiros" (SHIROMA; MORAES, EVANGELISTA, 2007. p. 46). Salienta-se, portanto, com Collor o processo de ajuste da economia brasileira às determinações da reestruturação da economia global, do neoliberalismo que se espraiava com força. Com essa postura do governo brasileiro, "abriu-se prematuramente o mercado doméstico aos produtos internacionais, em um momento em que a indústria nacional, em meados dos anos de 1980, mal iniciara seu processo de restruturação produtiva" (SHIROMA; MORAES, EVANGELISTA, 2007. p. 46- 47).

As mudanças bem como as técnicas de gestão da força de trabalho foram apresentadas como possibilidades de um trabalho qualificado, que envolve, continuamente, os trabalhadores na execução de suas atividades. Instala-se uma estrutura produtiva mais flexível, apelando à desconcentração produtiva, empresas terceirizadas, etc.. Empregam-se com isso, novas "técnicas de gestão da força de trabalho", as quais se concentram no trabalho em equipe, nas 'células de produção', nos 'times de trabalho' e nos 'grupos semi-autônomos'." (ANTUNES, 1999, p. 52). Passa-se a viver, conforme Antunes, um período de liofilização organizativa, com transferência, terceirização, eliminação e enxugamento de setores produtivos. Esse período, de uma maneira geral, insere-se no que Mézsáros classifica como a crise estrutural do capital, pois "não há nada especial em associar-se capital a crise. Pelo contrário, crises de intensidade e duração variadas são o modo natural de existência do capital, ou seja, são maneiras de progredir para além de suas barreiras imediatas e, desse modo, estender com dinamismo cruel sua esfera de operação e dominação" (MÉSZÁROS, 2009, p. 794).

Logo, atestam Antunes (1999), Mészáros (2009) e Harvey (1998, 2008), à medida que a crise estrutural do capital se avizinhou, o modo de produção capitalista tratou de se reorganizar, tendo como foco a "intensificação das condições de exploração da força de trabalho, o que acaba reduzindo muito ou eliminando tanto o trabalho improdutivo, que não cria valor, quanto suas formas assemelhadas" (ANTUNES, 1999, p.53).

Assim, no estabelecimento das concepções ideológicas que permearam o período, na defesa da reestruturação produtiva e da "reforma do Estado" destaca-se Bresser Pereira, tendo em vista as obras publicadas sobre a temática, bem como o fato de ser o ministro do MARE- Ministério da Administração e Reforma do Estado. Dentre as publicações dos "Cadernos do Mare" algumas foram escritas por Bresser Pereira, como, por exemplo, "A Reforma do Estado dos anos 90: Lógica e Mecanismos de Controle", que 
foi apresentada à segunda reunião do Círculo de Montevidéu em Barcelona, publicado entre outros veículos, na série de Cadernos MARE em 1997.

Nesse artigo Bresser Pereira apresenta a "reforma do Estado" que envolve quatro problemas principais:

[...] um problema econômico político - a delimitação do tamanho do Estado, [...] a redefinição do papel regulador do Estado; [...] a recuperação da governança ou capacidade financeira e administrativa de implementar as decisões políticas tomadas pelo governo e um político - o aumento da governabilidade ou capacidade política do governo de intermediar interesses, garantir legitimidade, e governar. (BRESSER PEREIRA, 1997, p.7).

Ele salienta ainda, que na delimitação do tamanho do Estado estão envolvidas as ideias de privatização, publicização e terceirização e que a "desregulação diz respeito ao maior ou menor grau de intervenção do Estado no funcionamento do mercado". Afirma que a questão da governança relaciona-se ao aspecto financeiro, que é a superação da crise fiscal, um estratégico que envolve a redefinição das formas de intervenção no plano econômico-social, um administrativo a superação da forma burocrática de administrar o Estado, e defende que no aumento da governabilidade é preciso a legitimidade do governo perante a sociedade, e a adequação das instituições políticas para a intermediação de interesses. (BRESSER PEREIRA, 1997). Salienta ainda que, a recuperação do Estado significa:

[...] recuperação da poupança pública e superação da crise fiscal; redefinição das formas de intervenção no econômico e no social através da contratação de organizações públicas não estatais para executar os serviços da educação, saúde e cultura; e a implantação de uma administração pública gerencial. Reforma que significa transitar de um Estado que promove diretamente o desenvolvimento econômico e social para um Estado que atue como regulador e facilitador ou financiador a fundo perdido desse desenvolvimento. (BRESSER PEREIRA, 1997, p. 17). Grifos nossos.

Assim, conforme o autor, no que se relaciona à delimitação da área de atuação do Estado, ela é necessária, pois o Estado cresceu em termos de pessoal, e principalmente, em termos de receita e despesa. Dentre as linhas fundamentais que permearam essa reforma Bresser Pereira (1997) defendeu, portanto, a delimitação da área de atuação do Estado, a desregulação, o aumento da governança e da governabilidade, por meio de um modelo baseado na reforma administrativa e no ajuste fiscal, que se sustentam na alegação da distinção entre a "propriedade estatal, a pública não estatal e a privada", culminando com sua referência à "propriedade pública não estatal", cujo destaque se daria por meio da "lógica do leque de controles", em que os mecanismos de "controle das sociedades capitalistas contemporâneas obedecem a uma graduação que vai do controle pelo mercado ao controle hierárquico tradicional". (BRESSER PEREIRA, 1997, p. 52). 
Trata-se, de um Estado competitivo, que contratará competitivamente organizações públicas não estatais, que pressupõe cidadãos menos protegidos ou tutelados pelo Estado, porém, mais livres, na medida que se torna "ele mesmo competitivo e requer cidadãos mais individualistas porque mais conscientes dos seus direitos individuais, mas também, mais solidários" (BRESSER PEREIRA, 1997, p. 52-53). A própria afirmação do autor torna evidente o tipo de cidadania e de cidadão que se pretendia nessa conjuntura, bem como o Estado que seria necessário para essa realização.

O Plano defendido por Bresser Pereira a serviço do governo brasileiro, portanto, propõe uma reforma do aparelho de Estado, com o propósito de tornar a administração pública mais eficiente. Esta "reforma" distingue o Estado em quatro setores: o Núcleo Estratégico, responsável pela elaboração, legislação e controle da execução das políticas públicas; o Setor de Atividades Exclusivas, no qual são prestados serviços de responsabilidade única do Estado, como: educação básica, segurança, previdência básica, por exemplo; o Setor de Bens e Serviços para o Mercado, que se refere às empresas público-estatais; e o Setor de Serviços Não-Exclusivos no qual " o Estado atua em conjunto com organizações do setor privado, chamado de 'setor público não-estatal', em serviços como: educação, saúde, cultura e pesquisa científica". (BEHRING, 2008, p. 138).

Em síntese, a organização ou administração pública eficaz que não se limita a estratégias de gestão, mas envolve mais do que mudanças organizacionais. Isso porque "implica mudanças na estrutura do Estado e, também, envolve todo tipo de parcerias público-privadas, porque os serviços sociais e científicos que a sociedade exige que 0 Estado forneça são terceirizados para organizações não estatais" (BRESSER PEREIRA, 2008, p. 394-395).

Nesse prisma, se apresentam as Organizações Sociais - OS, nos "Cadernos MARE da Reforma do Estado, Caderno 2": "a implementação de organizações Sociais é uma estratégia central do Plano Diretor de Reforma do Aparelho do Estado", no qual confirmase, nessa lógica, a defesa da parceria público-privado. Compreende-se, nesse caso: "Seu propósito mais genérico é permitir e incentivar a publicização, ou seja, a produção não lucrativa pela sociedade de bens e serviços públicos não exclusivos do Estado". (BRASIL, MARE, 1998, p. 8). Logo, o objetivo central do projeto de OS é proporcionar um marco institucional de transição de atividades estatais para o terceiro setor e, com isso, contribuir para o aprimoramento da gestão pública estatal e não- estatal. À primeira vista, esse objetivo parece sinalizar que se trata de algo que é bom para o Estado que, por sua vez, 
poderia beneficiar a população. Esta, no entanto, não é a realidade, pois trata-se sim, de uma forma de desviar recursos públicos para instituições e/ou grupos privados.

Instala-se, assim, um Estado regulador, tendo a publicização como uma estratégia no que diz respeito ao setor em que se encontram "as universidades, os hospitais, os centros de pesquisa e os museus". (BRASIL, MARE, 1998, p. 10), buscando, ao mesmo tempo, o controle social direto e a participação da sociedade, diga-se nesse sentido, desobrigar o Estado e lançar para a sociedade e por meio da regulação e controle por parte do Estado, as questões que envolvem a pesquisa, a ciência, a saúde e a educação.

Trata-se, portanto, de "propriedade pública não estatal, constituída pelas associações civis sem fins lucrativos, que não são propriedade de nenhum individuo ou grupo. As OS são um modelo de parceria entre o Estado e a sociedade". (BRASIL, MARE, 1998, p. 13). Peroni (2006) sublinha que com essas instituições o papel do Estado em relação às políticas sociais é alterado, tendo em vista que o propósito maior é a racionalização de recursos e o esvaziamento da autonomia das instituições, já que instituições democráticas são permeáveis às pressões e demandas da população, além de serem consideradas como improdutivas, pela lógica de mercado. Nessa contextura, "a responsabilidade pela execução das políticas sociais deve ser repassada para a sociedade: correspondendo aos propósitos neoliberais, o que deverá se dar por meio da privatização (mercado), e para a Terceira Via pelo público não-estatal (sem fins lucrativos)". (PERONI, 2006, p. 14.).

Diante desse contexto, importa, na sequência, tratar sobre as implicações desse modelo na gestão e condução do projeto desenhado para as universidades públicas e ensino superior em seu conjunto.

\section{A EDUCAÇÃO SUPERIOR NA DÉCADA DE 1990 NO BRASIL}

Na década de 1990, a educação superior não mereceu destaque especialmente na destinação de recursos e investimentos. A opção preferencial do governo federal brasileiro foi estimular a universalização do ensino fundamental, por meio do Fundo de Manutenção e Desenvolvimento do Ensino Fundamental e de Valorização do Magistério (FUNDEF) (DOURADO, 2008). Essa definição não se deu por acaso, visto que ela atendeu, sobremaneira, aos organismos internacionais e às agendas pactuadas, pois, com os empréstimos de ajuste estrutural voltados para a redefinição de políticas de Estado, o Banco Mundial, especialmente, assumiu o papel de liderança política e intelectual do modo de produção capitalista, em meio à crise, orquestrando e 
materializando sua interferência, tanto no ajustamento estrutural da agenda política internacional, quanto no setor econômico e financeiro, reverberando na política educacional dos países que fazem parte do conluio.

Fernando Henrique Cardoso escolheu para comandar o Ministério da Educação (MEC) o economista Paulo Renato de Souza. Paulo Renato foi reitor da Universidade Estadual de Campinas (UNICAMP) e assessor-técnico do Banco Interamericano de Desenvolvimento (BID). Essa escolha não foi por acaso, tendo em vista as vinculações entre as políticas educacionais do governo com as diretrizes estabelecidas pelos organismos políticos internacionais, em especial o Banco Mundial.

No que se relaciona ao ensino superior no Brasil, especialmente a partir do governo de Fernando Henrique Cardoso (1995-2003) que já durante sua campanha, em 1994, lançou o programa "Mãos à obra, Brasil: proposta de governo" e defendia que:

[...] a política científica e de formação de recursos humanos deve ter por objetivo dar estabilidade e condições de bom funcionamento aos melhores centros de pesquisa, grande parte dos quais localizados em universidades, além de dar condições para o surgimento de novos grupos de pesquisa nas diversas regiões do país; estabelecer vínculos mais estreitos entre a comunidade científica brasileira e a comunidade científica internacional. (CARDOSO, 2008, p. 42).

Essas medidas, entretanto, estão na perspectiva:

de criar mecanismos que estimulem e facilitem o desenvolvimento de projetos de cooperação científica e tecnológica entre universidades, institutos governamentais e o setor privado". Ainda, em conformidade com a proposta, a política para o ensino superior deve "promover uma revolução administrativa, que dê efetiva autonomia às universidades, mas que condicione o montante das verbas que recebem a uma avaliação de desempenho" e no que diz respeito ao número de "alunos que efetivamente formam, às pesquisas que realizam e aos serviços que prestam" (CARDOSO, 2008, p.42). (grifos nossos).

O Programa de Governo previa que as parcerias com o setor privado seriam parte importante do novo modelo de financiamento do desenvolvimento. Assim, no Governo Fernando Henrique na "redefinição do papel do Estado, caberá ao setor privado uma presença significativa, sobretudo nos investimentos em infraestrutura" (CARDOSO, 2008, p. 95.). Essa concessão dada pelo governo assegura que a OS possa receber determinados benefícios do Poder Público (dotações orçamentárias, isenções fiscais, cessão de bens e funcionários estatutários, etc.), mantendo uma ampla autonomia na gestão de suas receitas e despesas, estando livres das amarras regulatórias e burocráticas do aparelho de Estado. Mancebo (1998) sublinha que as garantias do Estado estariam condicionadas ao cumprimento dos termos firmados pelo contrato de gestão, o 
que significa que o controle por parte do Estado continuaria a ser exercido, através da vigilância administrativa sobre as metas e indicadores de desempenho alcançados pelas instituições.

No que diz respeito ao Ensino Superior, na LDB, são 14 artigos que, ao incorporar a lógica do público-privado, possibilita: "receber subvenções, doações, heranças, legados e cooperação financeira resultante de convênios com entidades públicas e privadas (art. 53 incisos (X e X)".

A LDB destina para a educação superior "um conjunto de princípios que indicam alterações para esse nível de ensino", sendo estas, balizadas, "de um lado, paradoxalmente, pelos processos ditos de descentralização e flexibilização presentes nessa legislação e, de outro lado, por novas formas de controle e padronização por meio de processos avaliativos estandardizados". (DOURADO, 2002, p.9).

Além da LDB, "um número importante de leis, medidas provisórias, decretos, decretos-leis, portarias, resoluções passou a definir os rumos do ensino superior brasileiro". (SHIROMA; MORAES; EVANGELISTA.2007, p. 78). A partir da aprovação da LDB em 1996, ocorreu a expansão das instituições de ensino superior, das instituições privadas de ensino, do ensino à distância - EAD e a ampliação da oferta de cursos tecnológicos, cursos noturnos, entre outros, o que, por si só, não modificou o quadro de acesso e permanência para a maioria da população, especialmente para a classe trabalhadora, que continuou ceifada do direito à universidade.

Após a aprovação da LDB e, "sobretudo, após 2002, efetivou-se um processo de credenciamento de instituições de educação superior para a oferta de cursos na modalidade a distância, com forte presença da esfera privada, particularmente, para a formação de professores". (DOURADO, 2008, p. 900),

Assim, embora, por um lado, tenha havido a expansão do ensino superior, e os dados revelarem incremento substantivo das matrículas,

[...] os indicadores ainda revelam os enormes desafios interpostos à garantia do acesso a esse nível de ensino, nos padrões aceitáveis internacionalmente e em consonância com as metas do Plano Nacional de Educação (PNE). Por sua vez, intensificou-se a lógica de expansão predominantemente privada (DOURADO, 2008, p. 895-896).

Além do incentivo às instituições privadas e aos cursos no formato de EAD, chamou a atenção, em relação ao ensino superior o "cenário sombrio da precarização de condições de trabalho e de infraestrutura que, em muitos casos, redirecionou as ações de gestão e organização acadêmica das IFES, com destaque para a secundarização das atividades de pesquisa em várias instituições. (DOURADO, 2008, p. 899). Ainda, como 
sublinha Dourado (2002), as políticas governamentais ao segmentarem a educação superior, por meio da expansão das matrículas e da diversificação institucional, naturalizaram esse campo como serviço, sendo que, na maioria dos casos, restringem a educação superior ao ensino.

No conjunto de medidas tomadas pelo governo em relação ao ensino superior e às universidades, a avaliação, ligada à eficácia e à produtividade, se coloca como marca, aliada a mudanças na gestão administrativa, ligadas ao ideário que permeia a conjuntura no neoliberalismo, pois,

[...] o neoliberalismo olha a educação a partir de sua concepção de sociedade baseada em um livre mercado cuja própria lógica produz o avanço social com qualidade, depurando a ineficiência através da concorrência. Com essa visão, o modelo das relações humanas é o 'empreendimento' que expressa o 'empreendedorismo', e nessa lógica, a organização mais desenvolvida é a empresa. (FREITAS, 2018, p. 31).

Por meio do controle, da avaliação e regulação, evidencia-se a ação que se coloca contrária ao caráter público das universidades, à medida que o sistema educacional, conforme Freitas, atinge a fronteira da eficiência quando a "atividade educacional estivesse sob controle empresarial concorrendo em um livre mercado". (Idem, p. 31).

Esse modelo foi seguido pelo ministro Paulo Renato de Souza, que conduziu a pasta de 1995 a 2002, caracterizado como um período de racionalizar, especialmente nas "IFES públicas, a gestão interna, o uso de recursos, a capacidade ociosa" e, "fundamentalmente, flexibilizar a criação de alternativas de cooperação e formação de parcerias no âmbito da sociedade civil". (SHIROMA; MORAES; EVANGELISTA, 2007, p. 78). Trata-se, portanto, de uma reforma em nome do resgate da "res-publica", pois fala-se da participação dos cidadãos no controle direto da administração pública, sendo que na esfera administrativa faz a crítica à gestão burocrática e sua substituição se dá pela administração gerencial "instala-se então, o controle pelos resultados e a ideia da eficiência e da qualidade como elementos da gestão empresarial que apontam para a flexibilização e a descentralização das decisões, o que espera-se, vai aumentar a eficiência do Estado". (BEHRING, 2008, p. 179) reverberando no ensino, e na gestão das universidades públicas.

A "reforma" implementada no Brasil, quanto à política educacional, de uma maneira geral, atendeu às exigências dos organismos internacionais (BM, BIRD e BID) para a concessão de novos empréstimos, condição indispensável para a consecução das políticas de ajuste fiscal propostas pelo governo (ALVES, 2000, SPINK, 2001). As 
recomendações do Banco Mundial para a educação superior como destaca Dourado (2002), prescrevem: a privatização do ensino superior; o estímulo à implementação de novas formas de regulação e gestão; a aplicação de recursos públicos nas instituições privadas; a eliminação de gastos com políticas compensatórias e a diversificação do ensino superior.

Neste contexto, a reestruturação da educação superior teve como marca a distinção e a diversificação das instituições de ensino, da oferta de cursos e a expansão de vagas, que se deu principalmente nas instituições privadas de ensino superior. Em relação às IES públicas, o balizamento se deu por meio do gerencialismo, do produtivismo e da implementação das políticas de avaliação. (DOURADO, OLIVEIRA, CATANI, 2003, p. 20).

Essas medidas materializaram-se na legislação relativa ao ensino superior. A autonomia universitária preconizada pelo governo $\mathrm{FHC}$ faculta às universidades ampla elasticidade em sua organização interna como: "a Criação de cursos, fixação de currículos, assinatura de contratos e convênios, execução de planos de investimento, administração de rendimentos, recebimento de subvenções, entre outros". (SHIROMA; MORAES; EVANGELISTA, 2007, p. 79).

Convém, entretanto, salientar, conforme as autoras, que o controle cabe ao Estado, por meio do credenciamento, das diretrizes e da avaliação permanente dos cursos de graduação e pós-graduação. Com a intensificação do controle, a avaliação passa a ser o mecanismo de julgamento dos cursos e das instituições, sendo instituído pelo Decreto $\mathrm{n}^{\circ}$ 2.026/96, que estabeleceu procedimentos para o processo e avaliação dos cursos e instituições de ensino superior, o Provão, revogado, mais tarde pelo Decreto $n^{\circ} 3.860$, de 9 de julho de 2001. Para a pós-graduação coube à Coordenação de Aperfeiçoamento de Pessoal de Nível Superior (CAPES) realizar a avaliação e o controle, e aos professores foi "imposto um mecanismo de avaliação exclusivamente quantitativa de sua produtividade. Trata-se da Gratificação de Estímulo à Docência (GED)". (SHIROMA; MORAES; EVANGELISTA, 2007, p. 79). Esses processos avaliativos resultam de alterações nos processos de gestão e de regulação do ensino superior provocando impactos na cultura institucional das instituições de ensino superior (DOURADO, 2002).

Assim, em relação ao ensino superior, a década de 1990, foi fecunda em exigir dos docentes envolvidos na pós-graduação nas IES um esforço de produção científica e desenvolvimento de pesquisa dissociado da política governamental para o ensino superior, à medida que realiza: "cortes de verbas para pesquisas, de taxas de apoio aos 
programas, de bolsas de estudo" (SHIROMA; MORAES; EVANGELISTA. 2007, p. 81). Dessa maneira, exige muito, fiscaliza e controla, ao mesmo tempo que precariza as condições de trabalho. Esses são alguns dos aspectos salientados pelas pesquisadoras, que levaram a década de 1990, à condição de "uma reforma na universidade sem reforma universitária". As políticas de expansão da educação superior, nesse período configuraram-se por meio de movimentos assincrônicos, bastante amplos e heterogêneos, permeados por práticas de natureza pública e privada. (DOURADO, 2002), com a predominância das de natureza privada.

O tempo passou e o Brasil dos anos 1990, foi ficando para trás. O país, a partir dos anos 2000 em diante, mergulhado na conjuntura neoliberal, passou por algumas mudanças que ampliaram o acesso e o ingresso de estudantes nas universidades, especialmente nos governos do PT. Convém, entretanto, destacar que mesmo nesses governos, os empresários da educação foram beneficiados, tendo em vista os rumos que tomaram as políticas do MEC no período, em que os interesses privados foram atendidos, por meio de programas como o PROUNI - Programa Universidade para Todos,- que destina vagas nas IFES privadas, por exemplo, - no caso do ensino superior, em nome de garantir vagas e acesso ao ensino superior. Entretanto, Saviani denuncia que: "[...] se há falta de vagas nas escolas públicas, com mais razão os recursos devem ser concentrados em investimento para criar mais vagas, não se justificando o repasse para escolas particulares". (SAVIANI, 2011, p. 83). O governo também criou o Programa de Apoio aos Planos de Reestruturação e Expansão das Universidades Federais - REUNI, - instituído pelo Decreto Federal $n^{\circ}$ 6.096, de 24 de abril de 2007, que se apresentou como uma política de expansão federal, para "reduzir distâncias geográficas e as desigualdades regionais na educação superior", o que estabeleceu contratos de gestão, por meio de parcerias público-privadas, semelhante ao que foi feito no PROUNI. Assim, o que se constata, é que, de uma maneira geral, a educação na conjuntura da globalização neoliberal desperta o interesse do setor privado, tornando-se um atrativo para empresários ávidos por lucro, mesmo em governos que se colocam como progressistas, como é o caso do PT.

A questão que se coloca agora, na sequência desse estudo, é como se encontra a sociedade, o Estado e o ensino superior, especialmente a universidade pública, pós governos do PT- com o impeachment da presidenta Dilma Roussef - que se caracterizou como um processo jurídico-político ocorrido em 2016 em nível de presidência da República, um "golpe de estado político" (NAPOLITANO, 2019, p.411). Assim, após o 
impeachment assume Michel Temer e, no final de seu governo, assume o governo brasileiro Jair Messias Bolsonaro que, eleito em 2018, iniciou seu governo em $1^{\circ}$ de janeiro de 2019.

\section{OS CAMINHOS DA EDUCAÇÃO SUPERIOR SOB A BATUTA DA PRIVATIZAÇÃO E DO CONTINGENCIAMENTO DE RECURSOS}

O Brasil, sob o governo Temer, adotou medidas calcadas na contenção da inflação, no controle dos gastos públicos e no incentivo aos investimentos privados, dando prosseguimento à estratégia que já vinha sendo adotada desde o início da desaceleração econômica em 2011. O desemprego alcançou $12 \%$ ao final de 2017 ; a economia permaneceu estagnada e as condições de vida da população sofreram queda. Isto, conforme Mancebo (2018), porque a vitória do rentismo institucionalizado na crise de 2008, foi responsável por aprofundar "as contradições estruturais da ordem burguesa no plano mundial e também no Brasil, principalmente no que tange ao orçamento público, impondo a adoção das políticas de ajuste (austeridade) neoliberal". (MANCEBO, 2018, p. 879).

A crise econômica mundial de 2008, no caso brasileiro, acabou eliminando "progressivamente as condições necessárias à manutenção do 'lulismo' e à sua estratégia de conciliação de classes, tornando cada vez mais evidente a incapacidade dessa estratégia em se manter como alternativa econômica, política e social". (MANCEBO, 2018, p. 879).

Temer, nessa lógica, além da reforma trabalhista, estabeleceu medidas, como por exemplo, a Emenda Constitucional $n^{\circ}$ 95, aprovada no final de 2016, com um mínimo destinado a determinadas áreas como saúde e educação para o valor vigente quando da implementação da regra, a ser ajustado a cada ano apenas pela inflação do ano anterior. Esta medida, no que concerne à educação, representa o abandono do princípio que norteia a vinculação constitucional dos recursos para a educação que é: à medida que não se assegura a educação como direito, e não apenas como privilégio de poucos, é necessário fixar repasse de recursos de acordo com as receitas do Estado e não apenas cortar e contingenciar.

Neste contexto, se estabelece uma série de medidas como o "PDV, reestruturações administrativas", fechamento e transformação de agências em postos de atendimento, como "a CEF - Caixa Econômica Federal, BB - Banco do Brasil, ECT - Empresa de Correios e Telégrafos" dentre outras. O objetivo, portanto, "nesta fase é aproveitar a 
conjuntura favorável e privatizar o que não foi possível fazer anteriormente, como tentou o governo FHC, mas não conseguiu". (FIGUEIREDO, 2017, p. 179).

Assim, é necessário salientar que a privatização das universidades públicas brasileiras não é algo recente; ela faz parte da trajetória do processo de privatizações no período mais recente da história brasileira, em que o governo FHC - Fernando Henrique Cardoso - se colocou como destaque, e é o que se faz presente, no contexto atual, com uma "importância crucial por ter se transformado em segmento altamente cobiçado por grupos privados nacionais e internacionais em face da possibilidade de aferição de altos índices de lucratividade" (FIGUEIREDO, 2017, p. 163). No contexto atual, verifica-se a influência de organismos internacionais com muita força no sentido de que aconteça a privatização das universidades públicas. O Banco Mundial, por exemplo, por meio do documento "Um ajuste Justo - análise da eficiência e equidade do gasto público no Brasil", orienta o governo para acabar com a gratuidade do ensino superior, tendo em vista que esta medida cortaria gastos sem prejudicar os mais pobres.

A partir de Temer, verifica-se uma mudança mais intensa na política das universidades públicas federais (FONSECA, 2018), no que diz respeito aos cortes de recursos, privatização e responsabilização das instituições pelo seu desempenho e ou fracasso - diga-se avaliações externas. Fonseca salienta que no orçamento do ano de 2017, pela primeira vez em décadas, ocorreu uma diminuição nominal no orçamento das universidades públicas. $O$ pesquisador sinaliza que esse fato é particularmente grave principalmente porque: "além do processo de expansão que ainda está em andamento, as maiores despesas de todas as universidades são na manutenção de contratos e serviços que não congelam e nem se reduzem, mas que todos os anos são reajustados". (FONSECA, 2018, p, 305). Passou-se a viver maiores cortes e contingenciamentos, tornando praticamente inviável o trabalho nas universidades públicas, sem investimentos em pesquisa, em materiais, em recursos humanos, além das campanhas em detrimento da ciência e da pesquisa.

Nesta esteira temos que:

[...] os traços que passam a ser perseguidos, e um modo geral, na educação superior brasileira são: pesquisa aplicada, cursos mais rápidos, inclusive apoiados em novas tecnologias de informação e comunicação; processos avaliativos ou de regulação calçados em resultados, dentre outros. Adicionalmente, cabe destacar a gradativa perda da autonomia universitária, diretamente relacionada à emergência de uma heteronomia de gestão e de uma nova relação entre universidade e setor empresarial, que começa a ter curso. (MANCEBO, 2017, p.883). 
Mancebo sinaliza para o fato de que a estratégia mais identificada é a dos cortes de verbas de manutenção e renovação das instituições, mas as dificuldades não se esgotam aí. Segundo a autora, outro movimento trata do enxugamento de suas funções, priorizando o ensino, em detrimento das demais atividades próprias do ensino superior. Paralela a estas questões, "o ensino - muitas vezes aligeirado, voltado às exigências de mercado ou ainda mediante o uso do EAD - nem sempre se encontra adaptado às necessidades dos novos estudantes". (MANCEBO, 2017, p.884-885).

Assim, se a educação já vinha sofrendo nos últimos anos o desmonte em relação ao ensino superior, este se intensificou com a entrada de Jair Bolsonaro (01/01/2019 a 31/12/2022), no governo brasileiro, que transformou o Ministério da Educação (MEC) em um ambiente de perseguição aos professores, aos estudantes e às ideias consideradas "pervertidas", - com o propósito de retirar das instituições públicas de ensino, o que seus partidários compreendem "como 'ideologias de esquerda', da influência dos partidos de esquerda colocando-a sob a influência da ideologia e dos partidos da direita, portanto, a serviço dos interesses dominantes" (SAVIANI, 2018, p.62).

Já desde a campanha eleitoral, o presidente Bolsonaro "direcionou grande parte de suas poucas palavras para atacar as universidades públicas e a educação pública em geral" (LEHER, 2019, p. 25). Na página do UOL, noticia já citada por Leher (2019), e visitada pela autora desse trabalho, vislumbra-se uma afirmação do presidente, em seu Twitter, proferida antes de sua posse, onde ele assegura que "uma das metas para tirarmos o Brasil das piores posições nos rankings de educação do mundo é combater o lixo marxista que se instalou nas instituições de ensino". (BOLSONARO, UOL, 2018), como se esta afirmação estivesse imbuída de verdades sobre o trabalho desenvolvido nas universidades.

O primeiro Ministro da Educação de Jair Bolsonaro foi Ricardo Vélez Rodríguez, colombiano naturalizado brasileiro, teólogo e filósofo. Este ministro causou muitas polêmicas principalmente com a Educação Superior, sendo uma delas a que envolveu as provas do Exame Nacional do Ensino Médio (ENEM) quando o INEP nomeou uma comissão para monitorar o exame e avaliar o conteúdo das provas. Essa comissão definida pelo MEC deveria ler as questões do banco de dados do MEC para analisá-las, fato que acabou levando a Procuradoria Federal dos Direitos do Cidadão (PFDC) e o Ministério Público Federal (MPF) a cobrar a posição adotada pelo MEC.

Ainda, durante o período de Vélez, houve a substituição de funcionários de carreira do MEC, por cargos de confiança do Ministro, também por militares, revelando uma clara 
alusão ao caráter autoritário do ministro. Essa, conforme Freitas (2018) é a "face autoritária da 'nova direita' neoliberal que foi deixada de lado nos últimos anos pela política de esquerda, e pode ser um fator importante para se entender os recentes acontecimentos no Brasil pós-2014". (FREITAS, 2018, p.26).

O Ministério da Educação durante o período de Vélez, portanto, apresentou uma série de distorções no que diz respeito à gestão democrática bem como o princípio da autonomia universitária - prerrogativa legal estabelecida no Brasil desde a Constituição Federal de 1988 e corroborada na LDB no 9. 394/96. Essas, entre outras celeumas, fizeram com que Jair Bolsonaro demitisse Vélez, e, para substituí-lo nomeasse Abraham Weintraub, professor licenciado da Universidade Federal de São Paulo (UNIFESP). Apoiador e integrante da equipe de transição de Bolsonaro, o professor Weintraub ocupou o cargo de secretário executivo da Casa Civil com Onyx Lorenzoni, um dos principais aliados do presidente. $\mathrm{O}$ ministro, logo ao assumir a pasta, intensificou os ataques à Educação Superior, anunciando corte de recursos, acusando as universidades de "balbúrdia", ameaçando especialmente cursos da área de humanidades, negando a ciência e a importância do conhecimento.

Dentre os anúncios de Weintraub, como Ministro da Educação, merece destaque, por parte do governo, o programa FUTURE-SE, - Programa Institutos e Universidades Empreendedoras e Inovadoras -, tendo em vista se apresentar como uma grande proposta de governo. O referido programa foi lançado em 17 de julho de 2019, e, conforme anunciado no próprio documento, tem o objetivo de dar "maior autonomia financeira a universidades e institutos por meio do fomento à captação de recursos próprios e ao empreendedorismo". (BRASIL, MEC, 2019, s/p). Importante salientar, que o lançamento do "FUTURE-SE" ocorreu em paralelo ao contingenciamento de verbas das universidades e institutos, justificado pelos gestores nacionais por conta da crise que o país enfrenta, para o que se faz necessário diminuir despesas, bem como, em nome da autonomia e de uma nova compreensão da gestão das IFES, - diga-se natureza privada da gestão.

Assim, em nome da crise retiram-se direitos e recursos em relação à educação superior, sendo o FUTURE-SE a alternativa apontada pelo governo. Ocorre que, com ele, não se evidencia nenhum compromisso com questões relativas a: a) ao acesso ao ensino superior; b) expansão da oferta de vagas, tanto na graduação, quanto na pós-graduação; c) o não atendimento às metas do PNE 2014-2024 -Lei no 13.005/2014, dentre outras 
reivindicações da classe trabalhadora, dos movimentos sociais, dos sindicatos dos docentes e demais categorias que defendem a universidade pública gratuita e laica.

Assim, o programa FUTURE-SE logo que foi lançado, passou a receber inúmeras críticas e muitas universidades o rejeitaram, tendo em vista as propostas contidas, como, por exemplo, a perda da autonomia da universidade, os contratos de gestão, o próprio financiamento público das instituições federais previsto no art. n 207 da Constituição Federal de 1988, referendado pelo Art. $n^{\circ} 55$ da LDB no 9.394/1996, quando estabelece que "Caberá à União assegurar, anualmente, em seu Orçamento Geral, recursos suficientes para manutenção e desenvolvimento das instituições de educação superior por ela mantidas", dentre outras medidas que afetam as instituições federais e têm como objetivo a privatização.

Por conta das críticas e da baixa adesão, o MEC abriu uma nova consulta pública sobre o FUTURE-SE, que ficou aberta até o dia 24 de janeiro de 2020 , e novamente foi levada ao Congresso para aprovação e sanção do presidente. A proposta do governo, entre outros pontos, cria um fundo de natureza privada para financiar as universidades e institutos federais. Este programa, bem como as demais ações do MEC, apresenta similitudes com as características identificadas durante a década de 1990, com a contrarreforma de Estado e políticas de aniquilamento do ensino superior.

As políticas para a educação superior no governo atual apresentam similitudes com as estabelecidas pelos governos na década de 1990, porém têm sido mais discrepante, especialmente ao tentar desqualificar o trabalho desenvolvido nas IFES, comprometendo as pesquisas, o ensino e a extensão - o sustentáculo dessas instituições -, ou seja, o tripé que as caracteriza como instituições científicas. Sobre a política de redução dos recursos para a área de ciência e tecnologia é importante salientar que não decorre da falta de receitas, pois, "desde 2013, os recursos provenientes dos fundos que constituem o Fundo Nacional de Desenvolvimento Científico e Tecnológico (FNDCT) são maiores do que os recursos destinados ao CNPq e à FINEP”. (LEHER, 2019, p.89).

Trata-se, portanto, de uma crítica ideológica feita por quem não tem condições de sustentá-la, lançando juízos de valor, negando a ciência e trazendo preceitos religiosos com ações que vão contra a educação, a ciência e a cultura, aliando-se a "grupos fundamentalistas - pentecostais e neopentecostais -, a extrema direita que sustenta um complô do comunismo internacional liderado pela China contra o Ocidente, e com adeptos de seitas de difícil definição" (LEHER, 2019, p. 14). 
Nessa perspectiva, além do FUTURE-SE, instalou-se uma intensa campanha contra os professores universitários designados por "zebras gordas" pelo ministro da educação². Esta situação apresenta semelhança com a perseguição auferida na década de 1990, quando servidores eram chamados de "marajás" "aproveitadores" etc. (MASCARENHAS, 2000, p.123).

Ainda, paralelo ao acossamento à classe trabalhadora, vive-se um processo de derrocada do que já se encontrava frágil: a democracia brasileira. Isto pode ser observado, por exemplo, em vários municípios brasileiros, nos quais são realizadas manifestações que têm com pauta pedidos para que Bolsonaro feche o Congresso Nacional, o Supremo Tribunal Federal e suspenda a democracia formal, por meio da implantação de uma ditadora militar, trazendo de volta os episódios do país de 1964 a 1985. Jair Bolsonaro tem sido incentivado nesta empreitada por seus apoiadores, entre eles o seu filho, Eduardo Bolsonaro e o general de Exército da reserva Augusto Heleno Ribeiro Pereira, que é o responsável pelo Gabinete de Segurança Institucional da Presidência da República.

No que diz respeito ao Estado, se na reforma de Estado dos anos 1990, visando à delimitação das funções do Estado, reduziu-se seu tamanho em termos principalmente de pessoal através de programas de "privatização, terceirização, publicização (este último processo implicando na transferência para o setor público não - estatal dos serviços públicos e científicos que hoje o Estado presta". (BRASIL, MARE, 1995, p. 18), no governo Bolsonaro esta determinação vem com muita força, aliada à defesa da necessidade de redução da carga tributária e das reformas administrativa e trabalhista - já aprovadas. O governo conta com o apoio do presidente da Câmara Federal Rodrigo Maia (DEM-RJ) neste intento, pois, conforme Maia, para diminuir o tamanho do Estado foi necessário fazer as reformas e diminuir despesas - isso inclui medidas contrárias aos interesses dos servidores federais para, posteriormente, simplificar os impostos, garantir o crescimento econômico e gerar mais recursos. Assim, "O salário do [funcionalismo] no governo federal é o dobro dos seus equivalentes no setor privado. O Estado, em vez de investir e distribuir, concentra; é preciso reorganizar essas despesas". (MAIA, 07/05/2020, s/p.).

\footnotetext{
${ }^{2} \mathrm{O}$ ministro da educação Abraham Weintraub, afirmou que para repor o orçamento do Ministério da Educação (MEC), iria atrás das zebras gordas, que é o professor de uma IFES com dedicação exclusiva que ganha de $\mathrm{R} \$ 15$ mil a $\mathrm{R} \$ 20$ mil por mês. O GLOBO, Jornal. 26 de outubro de 2019. Disponível em: https://oglobo.globo.com/sociedade/weintraub-afirma-que-vai-atras-da-zebra-gorda-professores-queganham-de-15-mil-r-20-mil-23976141. Acesso em 3 de janeiro de 2020.
} 
Nesta seara, com a criação das Organizações Sociais (OS) - proposta já evidenciada na década de 1990 nos cadernos do MARE -, que estarão diretamente envolvidas nas atividades fim das universidades, a dimensão já privatizada no âmbito das universidades por meio dos cursos de especialização lato sensu, defende-se uma intensificação na já proliferada criação de cursos de educação à distância. Compreendese, a partir dos Cadernos do MARE que o objetivo das OS é permitir e incentivar a publicização, a produção não lucrativa pela sociedade de bens e serviços públicos não exclusivos do Estado. (BRASIL, MARE, 1995), reforçando, portanto, a parceria públicoprivada, embora com a insígnia de "OS".

Enfim, o que se identifica com as ações propostas, é um projeto que desvaloriza a ciência, o conhecimento e especialmente o ensino público, sendo que a produção de bens públicos e o cultivo do bem comum são menosprezados e depreciados. Isto indica que a base das determinações governamentais não está calcada em estudos para a melhoria da educação superior pública no Brasil, mas na suposta eficácia gerencial do privado e na desvalorização da administração colegiada pública.

Como se pode perceber, de um lado, as investidas do governo são explícitas e ferem a autonomia, defendem os princípios do privado em detrimento do público, negam a importância da ciência e do conhecimento para as IFES públicas. Em conseqüência a tudo isto, identificam-se reações, que vão desde a invasão das ruas por parte de estudantes e servidores, como, por exemplo, os protestos de maio de 2019, seguidos pelos atos de 13 de agosto do mesmo ano, "que expressaram a indignação de estudantes e servidores contra os ataques às instituições federais e, genericamente, à cultura, à ciência e à educação básica, como se depreende da participação relevante de estudantes secundaristas" (LEHER, 2019, p. 13.).

Outro desmantelo deste governo foi o fato de não existir respeito em relação às decisões das instituições nas escolhas dos reitores, à medida que, valendo-se de brechas na lei que trata sobre este processo - o Decreto $n^{\circ} 1.916$, de 1996 que regulamenta o processo de escolha dos dirigentes de instituições federais de ensino superior, nos termos da Lei $n^{\circ}$ 9.192, de 21 de dezembro de 1995, - o presidente Bolsonaro tem desrespeitado as escolhas e nomeado, em alguns casos, professores que nem participaram do pleito em suas instituições, como, por exemplo, a nomeação de reitores Pro Tempore para os institutos federais de Santa Catarina (IFSC) e do Rio Grande do Norte (IFRN), para as universidades nos estados: Bahia, Ceará, Mato Grosso do Sul, Minas Gerais, Rio de Janeiro e Santa Catarina. Os reitores nomeados atendem às determinações do ministro e 
do presidente que se revelam contrários às instituições públicas de ensino, à ciência, à pesquisa, negando o conhecimento sistematizado à classe trabalhadora. Ainda, no mês de junho de 2020, o presidente enviou uma MP n 979 , que permitiria ao ministro da Educação nomear reitores temporários para as universidades e instituições de ensino superior federais sem consultar a comunidade acadêmica, A medida recebeu inúmeras críticas tanto da academia quanto de parlamentares, sendo devolvida ao governo pelo Presidente do Congresso Nacional, o que fez o presidente vetá-la.

Assim, várias ações e projetos do governo podem ser identificados, enquanto ignoram o que está implementado por meio da legislação como por exemplo, as alterações na LDB n 9.394/96, além de desconsiderar em vários aspectos o PNE - Lei no 13.005/2014, que está praticamente "obsoleto". Outro exemplo claro de alteração é a Resolução CNE/CP № 2, de 20 de dezembro de 2019, que define as Diretrizes Curriculares Nacionais para a Formação Inicial de Professores para a Educação Básica e institui a Base Nacional Comum para a Formação Inicial de Professores da Educação Básica (BNC-Formação), substituindo a Resolução CNE/CP n 02/2015, que havia sido aceita pela comunidade universitária por considerá-la resultado de um esforço coletivo. Importante salientar que a formação dos professores é importante especialmente no momento em que se concretiza a reforma da educação básica. A ANFOPE, bem como outras associações, se posicionou contrária à Resolução pois de acordo com o entendimento esta Resolução:

[...] é mais um retrocesso educacional pois descaracteriza a formação docente afrontando a concepção da Base Comum Nacional dos cursos de formação de professores, que articula indissociavelmente a formação e a valorização dos profissionais da educação, defendida historicamente pela ANFOPE. Essa aprovação acelerada, sem discussão, visa desmontar um processo em curso nas IES de todo o país, que nos últimos anos se dedicaram a reformular seus cursos de licenciatura conforme determinava a Resolução 02/2015, dentro do prazo previsto pelo CNE, que prorrogou sua implementação até dezembro de 2019.[...] Tal medida compromete a elevação da qualidade dos cursos de formação e da educação brasileira, e anula os avanços propostos pela Resolução 02/2015. (ANFOPE, et. al., 2019).

Existem, portanto, propósitos em relação à educação que envolvem desde a negação da ciência e do conhecimento, à intensificação da privatização e da publicização. Basta dizer quem tem voz e vez na definição de currículos, projetos e programas para o ensino e educação superior no Brasil: instituições privadas de ensino superior; empresas educacionais de capital aberto; Sistema $S$; movimentos empresariais; Organizações Sociais (OS), entre outros. Estabelece-se, portanto, uma reforma empresarial (FREITAS, 
2018), característica de instituições do espectro da educação privada, voltadas à manutenção do modo de produção diante da crise que se fez evidente. Isto se dá, tendo em vista a importância da educação para estes setores, com objetivos que destoam dos interesses da classe trabalhadora.

Evidencia-se, portanto, um ataque às instituições de ensino superior, à ciência e à tecnologia, o desmonte do Plano Nacional de Educação, da política de formação de professores e das políticas públicas, a negação do conhecimento científico, sob os auspícios de um governo que defende o obscurantismo, o desmantelamento do Estado de direito e dos ideais democráticos.

\section{5. À GUISA DAS CONSIDERAÇÕES FINAIS}

Este trabalho apresenta discussões iniciais, tendo em vista que trata sobre alguns aspectos que envolvem o ensino e a educação superior no Brasil, que ainda estão se consolidando. Trata-se, portanto, de estudo parcial que pretende contribuir para se pensar a respeito da temática, sem, contudo, esgotar o assunto. Neste sentido, apresenta algumas das propostas efetivadas após 2016, que contribuem com o desmanche da educação (FREITAS, 2018), bem como do ensino público (SAVIANI, 2008), que apresentam certa similitude com as ações impetradas na década de 1990 no Brasil, com a "Reforma do Estado" (BRESSER PEREIRA, 1997, p. 7).

Assim, durante a década de 1990, a opção preferencial do governo federal foi estimular a universalização do ensino fundamental, por meio do FUNDEF, para atender às agendas e aos organismos internacionais e estabelecer parcerias público privadas, o que já indicava que a educação na conjuntura da globalização neoliberal desperta o interesse do setor privado, tornando-se um atrativo para empresários insaciáveis na busca por lucro. Nesse período, a responsabilidade pela execução das políticas sociais foi repassada para a sociedade, pela privatização em acordo com os interesses neoliberais e pelo público não-estatal (sem fins lucrativos).

Caracterizou-se este período como de estímulo e facilitação do desenvolvimento de projetos de cooperação científica e tecnológica entre universidades, institutos governamentais e o setor privado. A política para o ensino superior deveria, portanto, promover uma mudança administrativa, por meio da "autonomia concedida" às universidades, condicionando o montante de repasses à avaliação de desempenho e ao número de estudantes que realmente seriam formados, ao tipo de pesquisas realizadas e aos serviços prestados à sociedade - diga -se à valorização do capital. 
Pode-se inferir, nesse prisma, em relação à educação e ao ensino superior, que a década de 1990 exigiu especialmente dos professores universitários - ainda mais dos que atuam na Pós-Graduação -, uma grande produção científica e desenvolvimento de pesquisa, ao mesmo tempo que, por parte dos governos, ocorreram cortes de verbas para pesquisas, de recursos para os programas de pós graduação, de bolsas de estudo, além do controle e fiscalização intensos que se implantam. (SHIROMA; MORAES; EVANGELISTA. 2007).

No que se relaciona ao período pós 2016, as ações, projetos e programas apontados até o momento intensificam o processo de privatização do que ainda resta de público e estatal, tendo em vista a privatização efetuada ao longo dos tempos. Instalou-se conforme Freitas (2018), um aparato jurídico parlamentar e midiático que se utiliza de subterfúgios e recursos ilícitos contra quem é considerado contrário às ideias, o que inclui a indicação de reitores para universidades e institutos federais - em alguns casos o terceiro colocado nas eleições em suas instituições e inclusive quem nem participou das eleições.

Assim, conclui-se que as políticas para a educação superior até o momento, apresentam similitudes com as estabelecidas pelos governos na década de 1990, porém têm sido mais discrepantes em alguns aspectos, especialmente ao tentar desqualificar o trabalho desenvolvido nas IFES, comprometendo as pesquisas, o ensino e a extensão - o sustentáculo dessas instituições -, ou seja, o tripé que as caracteriza como instituições científicas, públicas e com compromisso social.

\section{REFERÊNCIAS}

ALVES, Giovani. O novo (e precário) mundo do trabalho: reestruturação produtiva e crise do sindicalismo. São Paulo: Boitempo, 2000.

ANFOPE. A ANFOPE repudia a aprovação pelo CNE da Resolução que define as novas Diretrizes Curriculares para Formação Inicial de Professores da Educação Básica e Institui a Base Nacional Comum para a Formação Inicial de Professores da Educação Básica (BNCFormação), em sessão realizada no dia 07 de novembro, sem divulgação. Em um plenário esvaziado. [página online], 2019. Disponível em: http://www.anfope.org.br/anfope-repudia-aaprovacao-pelo-cne-da-resolucao-quedefine-as-novas-diretrizes-curriculares-paraformacao-inicial-de-professores-da-educacao-basica-einstitui-a-base-nacional-comumpara-a-formacao-inl. Acesso em 05/02/2020.

ANTUNES, Ricardo. Os sentidos do trabalho: ensaios sobre a afirmação e a negação do trabalho. São Paulo: Boitempo, 1999.

BEHRING, Elaine Rossetti. Brasil em Contrarreforma: desestruturação do Estado e perda de direitos. São Paulo: Cortez, 2008. 
BRASIL, MARE, Plano diretor de reforma do aparelho do estado. 1995. Disponível em: $<$ www.bresserpereira.org.br/.../MARE/PlanoDiretor/planodiretor.pdf>. Acesso em: 15 janeiro de 2020.

BRESSER PEREIRA, Luiz Carlos. A reforma do Estado nos anos 90: lógica e mecanismo de controle. Barcelona, 1997.

CARDOSO, Fernando Henrique. Mãos à obra Brasil: proposta de governo [online] Rio de Janeiro: Centro Edelstein de Pesquisa Social. 2008, 131 p. Available form SciELO Boocks.

DOURADO, Luiz Fernandes.; CATANI, Afrânio.; OLIVEIRA, João Ferreira. (Orgs.). Políticas e Gestão da Educação Superior: transformações recentes e debates atuais. São Paulo: Xamã, 2003.

DOURADO. Luís Fernandes. Políticas e gestão da educação superior à distância: novos marcos regulatórios? Educação e Sociedade, Campinas, v. 29,2008. pp. 891-917.Disponível em:<http://www.cedes.unicamp.br>Acesso:17/10/2019.

Reforma do estado e as políticas para a educação superior no Brasil nos anos 90.

Educação e Sociedade. Campinas, vol. 23, n. 80, setembro/2002, p. 234-252. Disponível em http://www.cedes.unicamp.br. Acesso dia 16/05/2020.

FIGUEIREDO, Júlio Carlos. Impeachment no Brasil: o Governo Temer e a privatização nas universidades públicas brasileiras. Germinal: Marxismo e Educação em Debate, Salvador, v. 9, n. 3, p. 161-181, dez. 2017.

FONSECA, Ricardo Marcelo. Democracia e acesso à universidade no Brasil: um balanço da história recente (1995-2017). Educar em Revista, Curitiba, Brasil, v. 34, n. 71, p. 299-307, set./out. 2018.

FREITAS, Luis Carlos de. A reforma empresarial da educação: nova direita, velhas ideias. São Paulo: Expressão Popular, 2018.

FRIGOTTO, Gaudêncio. Educação e Crise do Trabalho. Rio de Janeiro: Vozes, 1999.

GOLDESTEIN, Lídia. Repensando a dependência. Rio de Janeiro: Paz e Terra, 1994.

HARVEY, David. A condição pós-moderna: uma pesquisa sobre as origens da mudança cultural. 7. ed. São Paulo: Loyola, 1998.

Condição pós-moderna. 4. ed. São Paulo: Loyola, 1994.

O neoliberalismo: história e implicações. São Paulo: Loyola, 2008.

LEHER, Roberto. Autoritarismo contra a universidade: o desafio de popularizar a defesa da educação pública. 1.ed. - São Paulo: Fundação Rosa Luxemburgo, Expressão Popular, 2019. MAIA, Rodrigo. Agência Câmara Notícias. Segundo Maia, reformas voltam à agenda da Câmara no $2^{\circ}$ semestre e precisam ser mais amplas. Agência Câmara de Notícias. Disponível em: $\quad$ https://www.camara.leg.br/noticias/659820-segundo-maia-reformas-voltam-a-agenda-dacamara-no-2o-semestre-e-precisam-ser-mais-amplas/ Acesso em 07/05/2020.

MANCEBO, Deise. Crise político-econômica no Brasil: breve análise da educação superior. Educação e Sociedade, Campinas, v. 38, nº. 141, p.875-892, out.-dez., 2017.

MASCARENHAS, Ângela Cristina Belém. Desafiando o Leviatã: sindicalismo no setor público. Campinas: Alínea, 2000.

MÉSZÁROS, Istvan. A crise estrutural do capital. Rio de Janeiro: Boitempo, 2009.

NAPOLITANO. Marcos. Golpe de Estado: entre o nome e a coisa. Estudos avançados, vol.33, n.96, pp.395-420. Epub 12-Ago-2019.

PAULANI, Leda Maria. Não há saída sem a reversão da financeirização. Estudos Avançados. 389. 2017. Disponível em: http://www.revistas.usp.br/eav/article/view/132414/128548. 
PERONI, V.; ADRIÃO, T. Mudanças na configuração do Estado e sua influência na política educacional. In: PERONI, V.; BAZZO, V.L.; PEGORARO, L. (Org.). Dilemas da educação brasileira em tempos de globalização neoliberal: entre o público e o privado. Porto Alegre: UFRGS, 2006. p. 11-23.

POCHMANN, Marcio. Desempregados do Brasil. In: ANTUNES, Ricardo (Org.), Riqueza e miséria do trabalho no Brasil. São Paulo: Boitempo, 2007, p. 59-73.

RECK, Janriê Rodrigues; BITTENCOURT, Caroline Muller. A jurisprudência do STF sobre impeachment e suas repercussões aos Prefeitos Municipais em uma perspectiva discursiva. Revista de Investigações Constitucionais, v.3, n3p. 191-214,2016.

SAVIANI, Dermeval. A nova lei da educação: trajetória, limites e perspectivas. 12. ed. Revista, Campinas, SP: Autores Associados, 2011.

. O projeto "escola sem partido" na luta de classes da atual conjuntura política brasileira. In: História e historiografia da educação: debates e contribuições. Luciana Cristina Salvatti Coutinho Régis Henrique dos Reis Silva; José Claudinei Lombardi; Mara Regina Martins Jacomeli (Orgs.). Uberlândia / Minas Gerais Navegando Publicações. 2018, p. 49-64.

. Escola e democracia. 40. ed. Campinas, São Paulo: Autores Associados, 2008.

SHIROMA, Oto Eneida; MORAES, M. C.; EVANGELISTA, Olinda. Política educacional. Rio de Janeiro: DP7A, 2007.

SPINK, Peter Kevin. O Lugar do Lugar na Análise Organizacional. Revista de Administração Contemporânea, v. 5, p. 11-34, 2001.

THE WORLD BANK. Um Ajuste Justo - Análise da Eficiência e Equidade do Gasto Público no Brasil. Disponível em: https://www.worldbank.org/pt/country/brazil/publication/brazilexpenditure-review-report. Acesso em 20 de janeiro de 2020.

UOL, Brasília. Na véspera da posse, Bolsonaro critica lixo marxista nas escolas. Disponível em: https://noticias.uol.com.br/politica/ultimas noticias/2018/12/31/bolsonaro-marxismo-escolas.htm. Acesso em 05/0/2020. 